How to do it? / Nasıl yapılır?

\title{
Surgeon-modified fenestrated stent graft deployment in type B aortic dissection
}

\author{
Tip B aort diseksiyonunda cerrah tarafından modifiye edilmiş fenestere stent greft kullanımı
}

\author{
Hakkı Zafer İscan ${ }^{(0,}$, Ertekin Utku Ünal [ \\ Department of Cardiovascular Surgery, Ankara City Hospital, Ankara, Turkey
}

\begin{abstract}
The treatment of aortic dissections and aneurysms may be challenging for vascular surgeons. Currently, thoracic endovascular aortic repair is usually the first treatment option for descending aortic pathologies. Left subclavian artery coverage during this procedure is often required to achieve a sufficient proximal landing zone. Most surgeons agree that the left subclavian artery can be selectively covered, but revascularization is preferred to reduce the risk of neurological or ischemic complications. The chimney method, hybrid operations with extra-anatomic bypass, back table or in situ fenestrations are assistive techniques in this procedure. Herein, we present a surgeon-modified fenestrated stent graft for a type B aortic dissection patient.
\end{abstract}

Keywords: Aortic dissection, endovascular technique, fenestrated, subclavian artery, thoracic endovascular aortic repair.

The treatment of aortic dissections and aneurysms are always challenging for vascular surgeons. Thoracic endovascular aortic repair (TEVAR) provides less invasiveness and low morbidity and mortality. It is an effective and first treatment option for both complicated and uncomplicated type B aortic dissections (TBADs) by achieving thrombosis of false lumen, covering the primary tear, and allowing aortic remodeling.

The left subclavian artery (LSA) coverage is often required to achieve a favorable proximal landing zone during TEVAR. Extra-anatomic surgical bypass, chimney method, back table fenestration or in situ fenestrations are assistive techniques to sustain the flow of LSA.

The applicability of custom made endografts is limited due to economic conditions and time-consuming $\ddot{o} Z$

Aort diseksiyonları ve anevrizmalarının tedavisi damar cerrahları için zorlayıcı olabilmektedir. Günümüzde torasik endovasküler aort tamiri, inen aort patolojilerinin tedavisinde genellikle ilk tedavi seçeneğidir. Bu işlem sırasında yeterli bir proksimal oturma bölgesi sağlamak amacıyla sıklıkla sol subklaviyen arterin kapatılması gerekebilmektedir. Çoğu cerrah sol subklaviyen arterin kısmen kapatılabileceğini düşünmekle birlikte, nörolojik ve iskemik komplikasyonlardan kaçınmak amacıyla revaskülarizasyon tercih edilmektedir. Baca yöntemi, ekstra anatomik baypas ile hibrid operasyonlar, steril alanda veya in situ fenestrasyonlar bu işlem için yardımcı tekniklerdir. Bu yazıda, tip B aort diseksiyonu olan bir hastada cerrah tarafından modifiye edilmiş fenestre stent greft işlemi sunuldu.

Anahtar sözcükler: Aort diseksiyonu, endovasküler teknik, fenestere, subklavyen arter, torasik endovasküler aort tamiri.

manufacture delays. However, surgeon-modified fenestrated stent graft (SMFSG) seems to be a rapid and reliable solution to overcome this issue. Herein, we present SMFSG performed in a TBAD patient.

\section{CASE REPORT}

A 52-year-old male patient with subacute TBAD was referred to our clinic for rapid growth of aorta (5 $\mathrm{mm}$ in a week) and intractable pain. Procedure planning and device sizing were performed using a three-dimensional vascular imaging workstation (HOROS v3.3.6; The Horos Project, Public License). The diameter of the supra-aortic branches, distance between the branches, and the clock position of each branch was determined (Figure 1). Oversizing was planned as $10 \%$ for both proximal and distal ends. Therefore, a tapered $34 \times 26 \times 200-\mathrm{mm}$ stent graft

Received: August 23, 2020 Accepted: October 07, 2020 Published online: April 26, 2021

Correspondence: Ertekin Utku Ünal, MD. Ankara Şehir Hastanesi Kalp ve Damar Cerrahisi Kliniği, 06800 Çankaya, Ankara, Türkiye. Tel: +90532 - 6570637 e-mail: utkuunal@gmail.com 


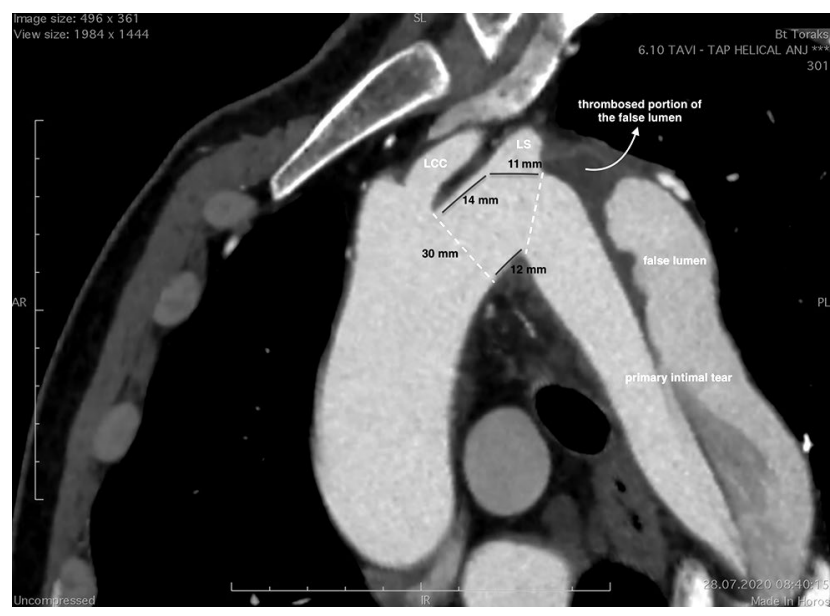

Figure 1. Preoperative planning on multiplanar reformation images. Diameter of aortic arch selected as the proximal landing zone (Zone 2) was $30 \mathrm{~mm}$. Proximal landing zone length was $25 \mathrm{~mm}$ at greater curvature and $11 \mathrm{~mm}$ at lesser curvature. The diameter of LSA was $11 \mathrm{~mm}$. The dissection was extended to the LS artery where the false lumen was partially thrombosed. (LCC: left common carotid artery, LSA: left subclavian artery).

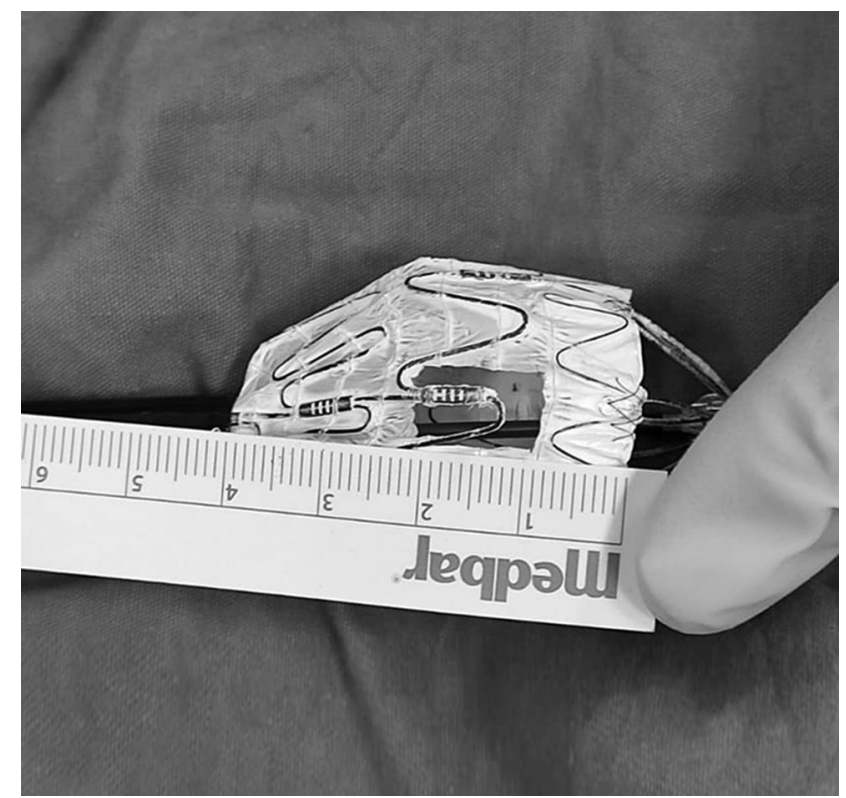

Figure 2. A 5 to $6-\mathrm{cm}$ unsheathed stent graft with surgeonmodified fenestration.
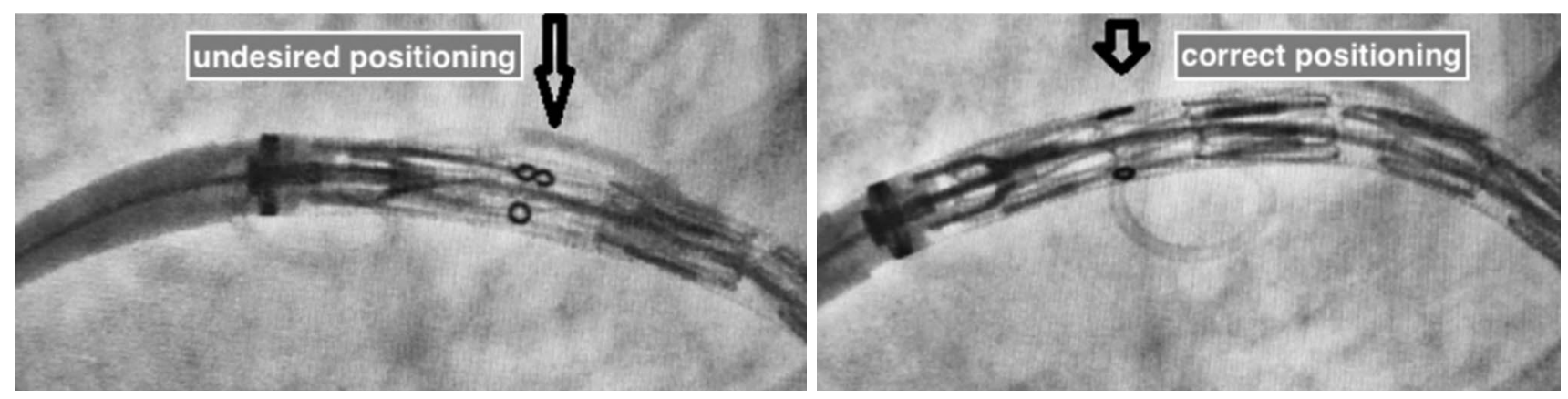

Figure 3. Correct positioning before deployment with radiopaque markers. Marker ' 8 ' should be oriented as a line to maintain the fenestration at the superior part of aortic arch.
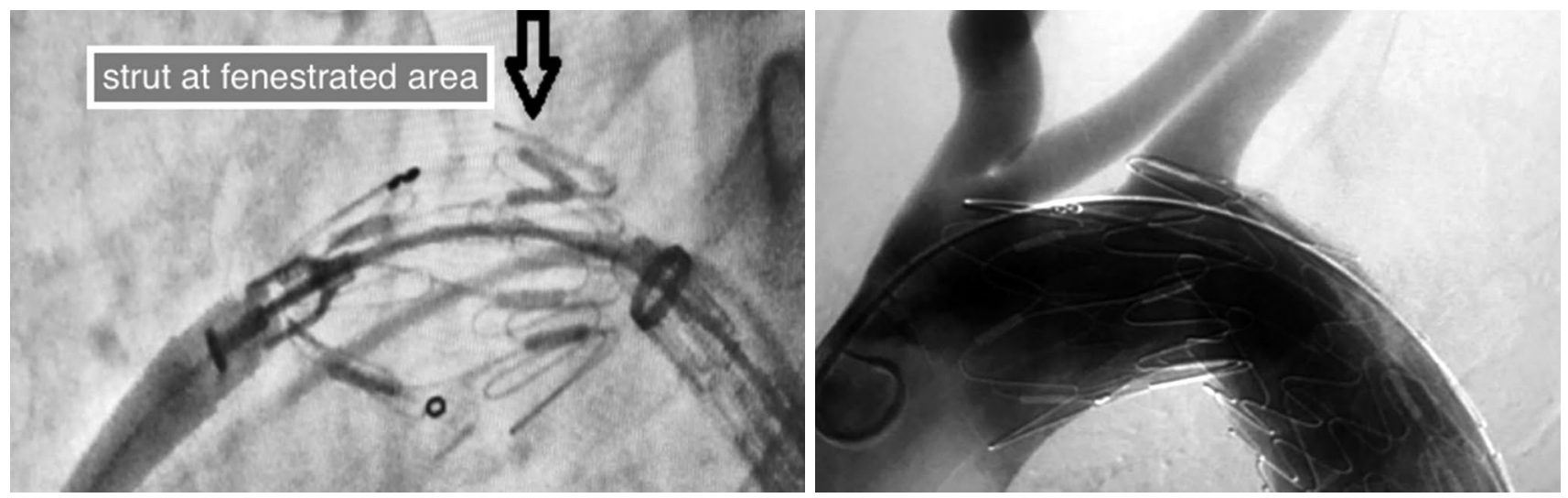

Figure 4. The strut at the fenestrated area protruding to the left subclavian artery on completion angiography. 

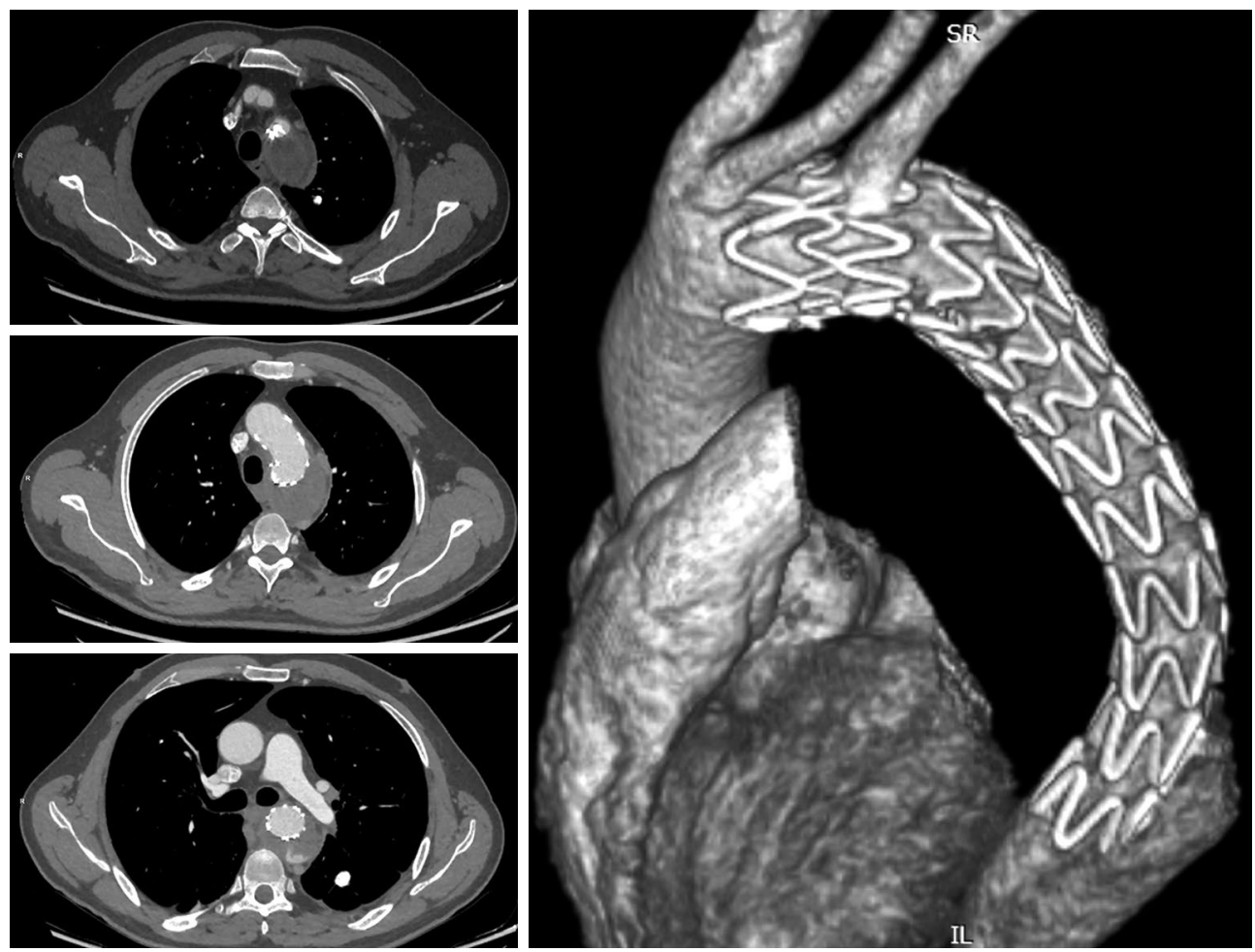

Figure 5. Computed tomography with three-dimensional reconstruction at first month. Bare strut at the orifice left subclavian artery can be seen at the left upper image. Initiation of thrombosis of the false lumen is obvious at axial images.

(Ankura $^{\text {TM }}$ TAA Stent Graft, Lifetech Scientific, Shenzen, China) was selected for the procedure.

The procedure was performed under general anesthesia in the hybrid operating room. Right femoral artery surgical exposure was performed and left percutaneous femoral artery access was obtained. After heparin administration, pigtail catheter was inserted up to the aortic arch for the true-false lumen control. Following the initial angiographic control of the aortic arch, the stent graft was unsheathed up to one strut distal to predicted fenestration area ( 5 to $6 \mathrm{~cm}$ ) on the surgical back table. The endograft covering material (expanded polytetrafluoroethylene [ePTFE]) was fenestrated using an 11-sized scalpel and, after the fenestration, the struts were cauterized for the left over the fabric materials (Figure 2). Unsheathing procedure, fenestration, and resheathing procedure took only around $5 \mathrm{~min}$. Approximately $1-\mathrm{cm}^{2}$ single fenestration was made for LSA by giving a special attention to preserve the endograft integrity (Figure 2). While introducing the endograft, marker ' 8 ' should be on the greater curvature and seen as a line. Being able to read the marker ' 8 ' or ' 0 ' during fluoroscopy confirmed the malpositioning of the endograft (Figure 3). Once the fenestration was ensured to be oriented toward the supra-aortic target vessel, the deployment was performed. The mean arterial blood pressure was lowered to 50 to $60 \mathrm{mmHg}$ during deployment to optimize accuracy. Completion angiography showed the closure of primary tear, patency of LSA, and no type 1A endoleak (Figure 4). At one-month follow-up, computed tomography revealed a perfect positioning of the endograft, no endoleak, ongoing thrombosis of false lumen, and patency of LSA (Figure 5).

\section{DISCUSSION}

Safe proximal landing zone in TBADs is crucial for endovascular procedure. The LSA can be defined as an anatomical structure that limits the proximal extension of TBAD at the greater curvature. Therefore, targeted proximal landing zone usually involves LSA orifice for TBAD patients. The aortic wall involved in the dissection or hematoma is too fragile to be used as the proximal landing zone for TEVAR. The unfavorable proximal landing zone may increase the risk of retrograde dissection extending to the aortic arch. 
Most surgeons agree that LSA can be selectively covered; however, revascularization is usually preferred to reduce the risk of neurological or ischemic complications. ${ }^{[1]}$ On the other hand, preserving LSA is critical not only to avoid these complications, but also to sustain the flow of left internal mammary artery for a potential coronary artery bypass surgery.

The standard method of preserving LSA flow is the caroticosubclavian bypass, which requires an additional simultaneous or staged surgical procedure. Alternative endovascular techniques have been documented for LSA protection. ${ }^{[2,3]}$ Regarding the chimney technique of deploying parallel grafts to the aortic stent graft poses the risk of perigraft endoleaks. ${ }^{[4]}$ In situ needle fenestration is a potential revascularization technique; however, it is currently not available in Turkey and has a remarkable cost. $^{[2]}$ Branched endograft is another option, which has the disadvantages of waiting time with high cost, inevitably limiting its use. ${ }^{[3]}$

Currently, there is no custom-made fenestrated endograft or branched stent grafts due to economic/ marketing concerns in our country; therefore, a surgeonmodified fenestrated tapered TEVAR endograft was deployed in this case.

The SMFSG requires experience and a learning curve for accurate planning to position fenestrations. The experience of Canaud et al. ${ }^{[5]}$ with 24 patients treated by homemade fenestrations for native LSA demonstrated excellent early and midterm results with $100 \%$ technical success.

For a successful procedure, the surgeon has to be accustomed to the endograft used. The Ankura ${ }^{\mathrm{TM}}$ TAA Stent Graft has an ePTFE, dual-membrane material for biocompatibility and durability with nitinol endoskeleton. Stability and flexibility of the current grafts offer a chance to perform unsheath, fenestration, and resheath procedures easily. However, the radiopaque mark for increased accuracy is a concern for these grafts. Endograft has two differently shaped radiopaque markers (" 8 " and " 0 ") on each side of the proximal landing zone, which facilitates the positioning. The perfect positioning is ensured, when the 8 -shaped marker looks like a line. There is a connecting bar just distal to radiopaque marker " 8 " on the greater aortic curvature, and the bar avoids shortening and provides axial support as seen in Figure 2 . All efforts should be made to confirm this perfect configuration as seen in Figure 4.
Despite increasing experience, a margin of error in placing fenestrations always exists and the mismatch possibility may lead to complications. Aortic three-dimensional printing has been widely described in medicine for simulation, training, and surgical planning. This aortic model can be used for training to achieve or facilitate the precise location of fenestrations for a faster and more efficient procedure and better long-term results. ${ }^{[6]}$

Fenestrated stent graft technology requires preoperative accurate measurements to ensure precise matching of the native vessel and endograft fenestration. In this method, proper patient selection is the key to success. The anatomical limitations must be recognized, as the greatest attention should be given to the length between the left common carotid artery (LCCA) and LSA. It should be $\geq 10 \mathrm{~mm}$ to ensure endograft integrity and to create a healthier proximal landing zone. Fenestration for LCCA and LSA both seems to be feasible.

The main concern about fenestrations is the necessity of stenting aortic branches both for preserving the flow and avoiding endoleaks. Shu et al. ${ }^{[2]}$ very well documented the requirements of stenting. Firstly, the innominate artery and LCCA should be always stented, when the fenestrations include these branches. However, LSA stenting should be performed under some circumstances, such as imbalance between bilateral brachial artery blood pressure measurements and poor/delayed blood flow of LSA on completion angiography. Moreover, if there is no overlap of endograft and aorta at the site of LSA (i.e., aneurysmal aorta), type III endoleak would be inevitable and a covered stent to bridge LSA must be utilized.

The limitations for back table fenestration pose a risk for infection, increasing the possibility of spoiling the endograft integrity by the fenestration, and resulting in durability concerns. If there is spinning and rotation of the graft due to tortuosity and loss of orientation and alignment, a left brachial access for a bailout chimney stenting or surgical bypass may be performed. Another limitation is the absence of bench testing of SMFSG prior to clinical use. The question of fabric durability and endograft integrity still need to be evaluated. The fenestrated portion of the endograft is vulnerable to endoleaks, when the primary intimal tear is close to the proximal landing zone, which was not a case in our patient as seen in Figure 1. Moreover, the smooth continuity at the greater curvature of the aortic arch in dissection patients facilitates the application of this technique. 
The main anatomical limitation of SMFSG is in the case of no overlapping between the endograft and the aortic wall around the target vessels, i.e., at an aneurysmatic aorta. To overcome this limitation, SMFSG may be deployed and the fenestration can be cannulated from the left brachial access and a covered stent can be deployed to restore the flow and avoid endoleaks.

In conclusion, achieving successful results with a homemade device is a work of art. In this article, we describe a time-saving and low-cost method of preserving LSA flow during TEVAR procedure without sophisticated instruments. Pre- and intraoperative detailed accurate measurements are a must. On the other hand, being familiar to the stent graft used is of a great concern. However, durability concerns necessitate additional studies. Until fenestrated or branched endografts are manufactured with lower costs and become available without delay on the market or in situ needle fenestration avoiding orientation problem available, SMFSG is a fast, widely applicable, readily available, and effective treatment modality.

\section{Declaration of conflicting interests}

The authors declared no conflicts of interest with respect to the authorship and/or publication of this article.

\section{Funding}

The authors received no financial support for the research and/or authorship of this article.

\section{REFERENCES}

1. Matsumura JS, Lee WA, Mitchell RS, Farber MA, Murad MH, Lumsden AB, et al. The Society for Vascular Surgery Practice Guidelines: Management of the left subclavian artery with thoracic endovascular aortic repair. J Vasc Surg 2009;50:1155-8.

2. Shu C, Fan B, Luo M, Li Q, Fang K, Li M, et al. Endovascular treatment for aortic arch pathologies: Chimney, on-the-table fenestration, and in-situ fenestration techniques. J Thorac Dis 2020;12:1437-48.

3. Al-Hakim R, Schenning R. Advanced techniques in thoracic endovascular aortic repair: Chimneys/periscopes, fenestrated endografts, and branched devices. Tech Vasc Interv Radiol 2018;21:146-55.

4. Zhang L, Wu MT, Zhu GL, Feng JX, Song C, Li HY, et al. Off-the-shelf devices for treatment of thoracic aortic diseases: Midterm follow-up of TEVAR with chimneys or physician-made fenestrations. J Endovasc Ther 2020;27:132-42.

5. Canaud L, Morishita K, Gandet T, Sfeir J, Bommart S, Alric P, et al. Homemade fenestrated stent-graft for thoracic endovascular aortic repair of zone 2 aortic lesions. J Thorac Cardiovasc Surg 2018;155:488-93.

6. Barón V, Guevara R. Three-dimensional printing-guided fenestrated endovascular aortic aneurysm repair using open source software and physician-modified devices. J Vasc Surg Cases Innov Tech 2019;5:566-71. 